\title{
An analytical approach of Parametric Monitoring of Induction Motor Using GSM
}

\author{
Snehal Lande ${ }^{1}$, Pooja Jaiswal ${ }^{2}$, Priyanka Rajgure ${ }^{3}$ \\ ${ }^{1}$ (Extc, Sipna Coet/ Amravati University, India) \\ ${ }^{2}$ (Extc, Sipna Coet/ Amravati University, India) \\ ${ }^{3}$ (Extc, Sipna Coet/ Amravati University, India)
}

\begin{abstract}
Protection of induction motor against possible problems such as overvoltage, overcurrent, overspeed, overtemperature, three-phase unbalanced occurs in course of it's operation is very important because it is used intensively in industry as an actuator. Induction motor can be protected using some components, such as timers, contactors, voltage, and current relays. The voltages, currents,speed, and temperature are the parameters of the motor, andthe problems occurred in the system, are monitored by microcontroller ATMEGA-16 which communicates with GSM and GSM send messages are shown on the $L C D$ as well as on the mobile screen. Experimental resultsare presented in this paper which shows that the parameters of induction motor can be monitored using GSM which costs less, provides higher accuracy as well as safe and motorgets fully protected.
\end{abstract}

Keywords:ATMEGA-16, GSM,induction motor,monitoring,parameters.

\section{INTRODUCTION:}

The aim of this research paper is to monitor the parameters of induction motor because of the fast growth in the application of induction motor in sensitive areas such as nuclear power plants, has increased need of continuous condition for monitoring of motor .Condition monitoring of electrical machines and drive system is a vital factor to achieve efficient and profitable operation of large variety of industrial process. Similarly parameter estimation is important for the machine designer, invaluable to the operator of modern drives implementing various types of controllers. It is also necessary to know machines parameters for a numbers of simulation purpose [1].

Condition monitoring of induction motor have been a challenging task for engineers and researchers mainly in industries. There are many conditions monitoring methods including vibration monitoring, thermal monitoring, chemical monitoring all these monitoring methods required expensive sensors or specialized tools whereas parametric monitoring of induction motor using GSM does not required additional sensors. Here, we are used AVR microcontroller in which we used embedded system for its programming and its operation. In AVR microcontroller it gives internal flash programmable memory of $16 \mathrm{~kb}$ and inbuilt 512 bytes EEPROM and it contains four ports for its operation. The server is basically software interface with GSM modem which monitored the parameters of induction motor. This also contains AVR controller which generates controlled signals which is transmitted to server also makes use of mobile frequency band provides complete automation. This architecture is more efficient while achieving thought put to ten times faster than CISC microcontroller. It monitored overvoltage, overcurrent, over speed, over temperature, three-phase unbalancing by using microcontroller ATMEGA-16 which communicates with GSM and GSM send message to the user. Condition monitoring of induction motor is a process that may be used to great advantage in agricultural field and in the industrial application also.

To provide reliable condition monitoring and protection of motor this paper represents parametric monitoring which is useful in the following areas - thermal protection, temperature estimation, fault detection. For each category related feature of motor are discussed in terms of their robustness, accuracy and implementation complexity. In this paper we used components namely as GSM, LM 35, LCD, Power supply, Induction motor. 


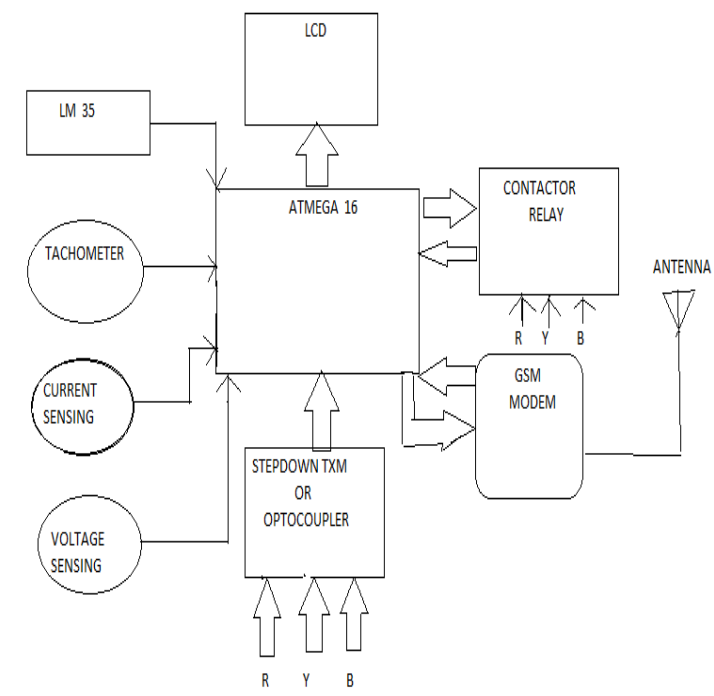

Fig 1.1 Block diagram of required system

\section{PROPOSED SYSTEM:}

In this we used ATMEGA-16 microcontroller which a low power CMOS 8-bit microcontroller based on AVR enhanced RICS architecture, having four ports namely- PORT-A, PORT-B, PORT -C, PORT-D respectively each of 8-bits. It contains inbuilt A to D converter of 8-channels [2]. Herewe provided three- phase supply R, Y, B. A device to which shaft is coupled and it rotates in the anticlockwise direction whereas rotation of the motor is in the clockwise direction. We can used step -down transformer or optocoupler, in this paper instead of step-down transformer can used optocoupler because .An optocoupler works on 5VDC but output of resistors is AC so to convert AC into DC we used bridge wave rectifier. One of the output of bridge wave rectifier is connected to the ground and another one is connected to optocoupler. It also contains stabilized voltage regulated IC i.e. 7805 which is used to provide constant voltage.

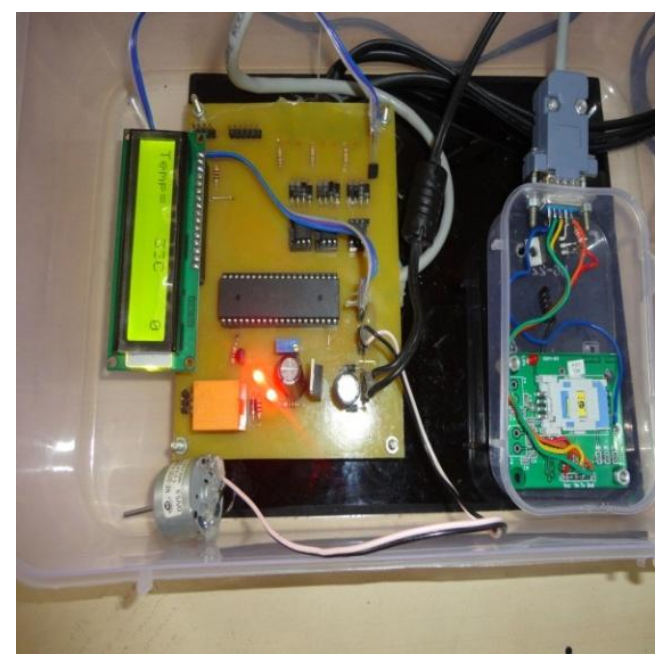

Fig 2.1: Overall view of system

The block schematics of proposed system are described below.

\section{2 .1 GSM:}

In this paper we used GSM than other access schemes such as CDMA,TDMA because CDMA is relatively new and network is not as matured as GSM , another reason is CDMA can't offer international roaming a large GSM advantageous CDMA is still building its network[3].

A GSM modem is specialized type of modem which accepts SIM card, and operate over a subscription to a mobile operator, just like mobile phone from mobile operator perspective GSM modem tools like a mobile phone.GSM also pioneered low-cost implementation of the short message service (SMS), also called text 
messaging, which has since been supported on other mobile phone standard as well GSM modems are most frequently used for sending and receiving SMS and MMS message. A GSM modem exposes interface that allow application such as SMS to send and receive message over modem interface. During the process, whatever faults occur can be displayed on the screen of mobile with the help of communication done between microcontroller and GSM because TXD of microcontroller is connected to RXD of GSM and RXD of microcontroller is connected to TXD of GSM. To perform these tasks GSM modem must support "extended AT command extended AT command set" for sending/receiving SMS message. GSM modem can be quick and efficient way to get started with SMS because special subscriptions to SMS service provider is not required. GSM modem is cost efficient solution for receiving SMS message because the sender is paying for the message delivery [4].

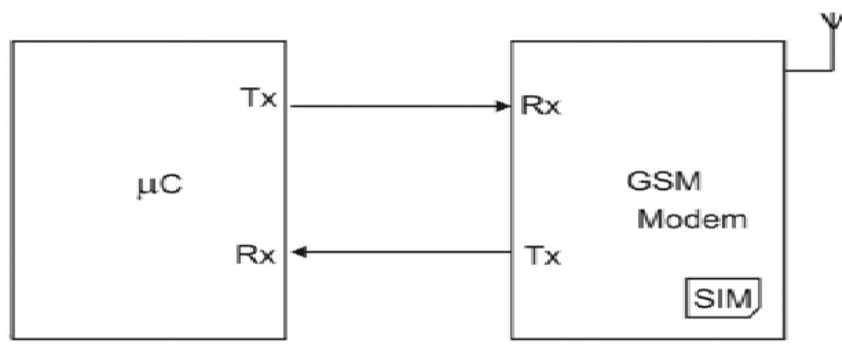

GSM Interfacing

Fig 2.2.GSM interfacing

\subsection{GSM Module:}

This GSM modem is a highly flexible plug and easy integration to RS232. Supports features like Voice, Data/Fax, SMS, GPRS and integrated TCP/IP stack. Historically, we have recommended GSM modems from manufacturers such as Multitaskand Siemens. While these manufacturers make very good GSM modems, there are currently a lot of GSM/3G USB stick modems available on the market, which are less expensive (under \$100), and in many cases significantly faster than older GSM modems .

GSM modems can be a quick and efficient way to get started with SMS, because a special subscription to an SMS service provider is not required. The mobile operator charges for this message sending and receiving as if it was performed directly on a mobile phone. In most parts of the world, GSM modems are a cost effective solution for receiving SMS messages, because the sender is paying for the message delivery. Some recommended GSM/3G USB modems include the Option ICON 322, Sierra Wireless Compass 885, Sony Ericsson MD300, M C 950D and Hawaii E160.

Many other models from these manufacturers will also work well [5].

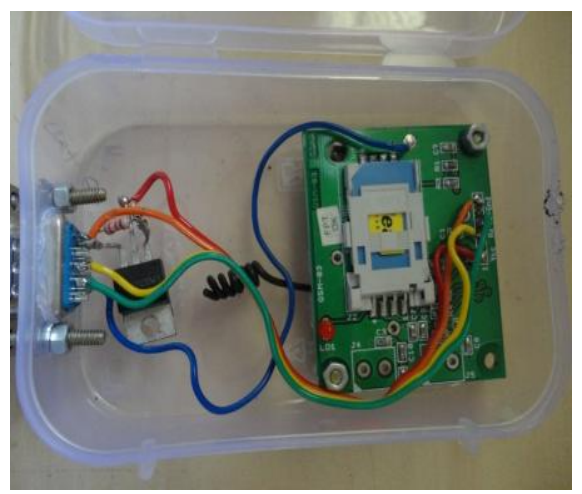

Fig 2.3. GSM Module

\subsection{LM 35:}

The LM35 series are precision integrated-circuit temperature sensors; the LM35 thus has an advantage over linear temperature sensors calibrated in ${ }^{\circ}$ Kelvin, as the user is not required to subtract a large constant voltage from its output to obtain convenient Centigrade scaling. The LM35 does not require any external Calibration or trimming to provide typical accuracies of $\pm 1 / 4^{\circ} \mathrm{C}$ at room temperature and $\pm 3 / 4^{\circ} \mathrm{C}$ over a full -55 
to $+150^{\circ} \mathrm{C}$ temperature range. The LM35's low output impedance, linear output, and precise inherent calibration. It can be used with single power supplies or with plus and minus supplies [7].

PLC:

We can use PLC instead of Microcontroller. This explains a PLC-based protection and monitoring method for a three-phase induction motor. The new solutions for various faults of the phase currents, the phase voltages, the speed, and the winding temperatures of an IM occurring in operation have been achieved with the help of a PLC. If only a PLC is used as a protection relay for a system, it costs more.

But the use of a PLC can be the right choice if it is considered in an automation system in order not to use extra microprocessor such as PIC Nowadays, the most widely used area of programmable logic controller (PLC) is the control circuits of industrial automation systems. The PLC systems are equipped with special I/O units appropriate for direct usage in industrial automation systems. The input components, such as the pressure, the level, and the temperature sensors, can be directly connected to the input. The driver components of the control circuit such as contactors and solenoid valves can directly be connected to the output. Many factories use PLC in automation processes to diminish production cost and to increase quality and reliability [8].

A programmable integrated circuit (PIC) based protection system has been introduced in. The solutions of various faults of the phase currents, the phase voltages, the speed, and the winding temperatures of an IM occurring in operation have been achieved with the help of the microcontroller, but these electrical parameters have not been displayed on a screen.

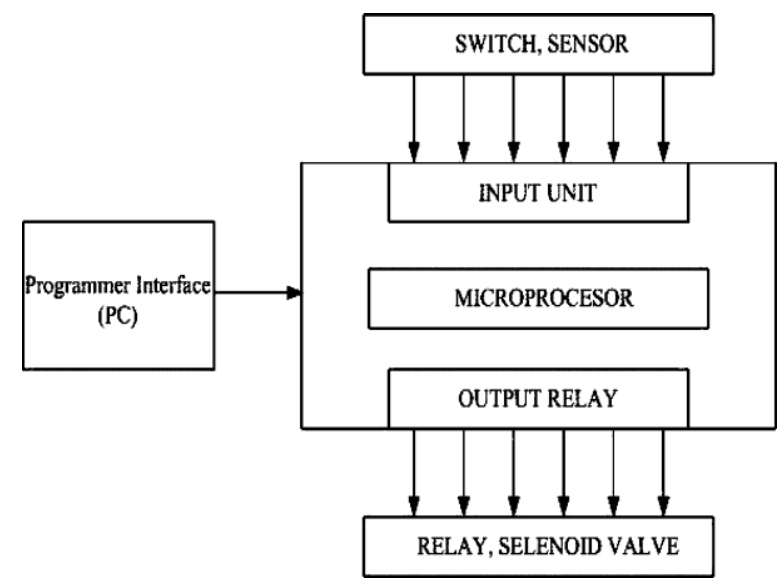

Fig 2.4. PLC (Programmable Logic Controller)

\subsection{LCD:}

A liquid crystal display (LCD) is a thin, flat electronic visual display that uses the light modulating properties of liquid crystals (LCs). LCs does not emit light directly. They are used in a wide range of applications including: computer monitors, television, instrument panels, aircraft cockpit displays, signage, etc. LCDs are more energy efficient and offer safer disposal than CRTs.

Its low electrical power consumption enables it to be used in battery-powered electronic equipment. It is an electronically-modulated optical device made up of any number of pixels filled with liquid crystals and arrayed in front of a light source (backlight) or reflector to produce images in color or monochrome [9].

FEATURES: Resolution versus range, Timing performance, Colorperformance, Color support. 


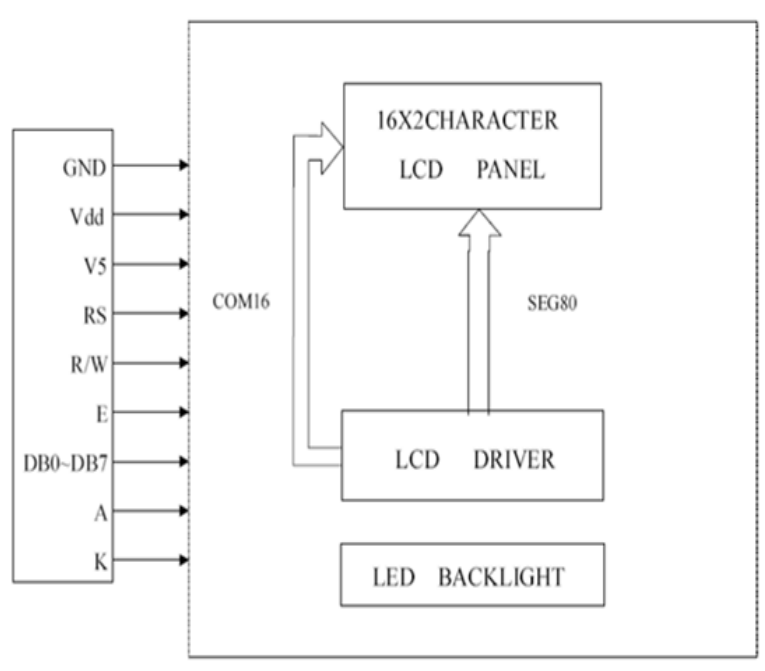

Fig 2.5: Block diagram of LCD

\subsection{INDUCTION MOTOR:}

An electric motor convert electrical energy into mechanical energy, most of the electric motor operates through interaction of magnetic field current carry conductor to generates force. The reverse process of producing electrical energy from mechanical energy is done by generators such as alternator or dynamo, some electric motors can used as generators. An induction motor is an asynchronous AC motor where power is transferred to the rotor by electromagnetic induction, much like transformer action. At low speeds, the current induced in the squirrel cage is nearly at line frequency and tends to be in the outer parts of the rotor cage. In a wound-rotor motor, the rotor winding is made of many turns of insulated wire and is connected to slip rings on the motor shaft. When used with a load that has a torque curve that increases with speed, the motor will operate at the speed where the torque developed by the motor is equal to the load torque. Reducing the load will cause the motor to speed up, and increasing the load will cause the motor to slow down until the load and motor torque are equal. Operated in this manner, the slip losses are dissipated in the secondary resistors and can be very significant. The speed regulation and net efficiency is also very poor [10]. When applying an AC drive system it helps to remember you are actually applying magnets to move a load. To move a load fast does not require more magnets, you just move the magnets fast. To move a heavier load or to decrease acceleration time (accelerate faster) more magnets (more torque) are needed. This is the basis for all motor applications [11].

\section{WORKING:}

Optocoupler contains internal transistor and LED. One of the output of bridge wave rectifier is connected to the optocoupler. When output is high at that instant LED glow as a result transistor is in the conducting mode. As mentioned in the above paragraph contains four port each of 8-bit, to which three output of the optocoupler is connected. The whole operation is performed on port-B and output is taken from port-C. ANDing operation is performed on port-B whenB.0, B.1, B.2 is 1 then the output is 1 else0. It has inbuilt ADC of 8-channel to which $\mathrm{CH}-0$ is used for temperature, $\mathrm{CH}-1$ is used for motor; $\mathrm{CH}-2$ is used for speed. GSM can communicates with microcontroller as TXD of microcontroller is connected to RXD of GSM and RXD of microcontroller is connected to TXD of GSM. In case of three-phase supply when one of the phase is disconnected at the sameinstant of time motor stop its working and message will displayed on the LCD as well as user. In case of speed, if speed is increased above $1000 \mathrm{rpm}$, then at the same instant of time motor will stop its working and message will displayed on the screen. Similarly, in case of temperature, when temperature is beyond 60 degree then it will stop its working and message will send as" overheated".

\section{RESULTS:}

CASE I- In case of three-phase supply when one of the phase is disconnected at the same instant of time motor stop its working message will be displayed on the LCD as well as user. 

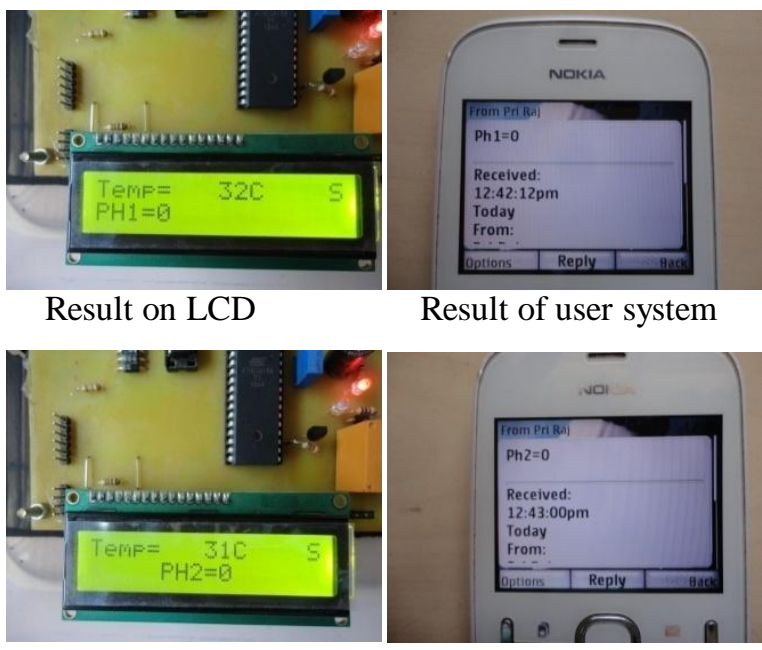

Result on LCD Result of user system

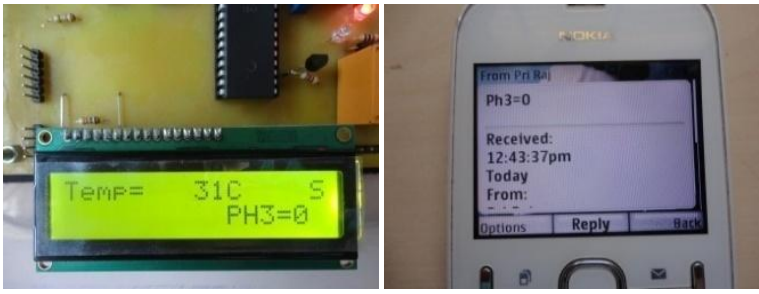

Result on LCD

Result of user system

CASE II- In case of speed, if speed is increased above $1000 \mathrm{rpm}$, then at the same instant of time motor will stop its working and message will displayed on the screen as well as user system.

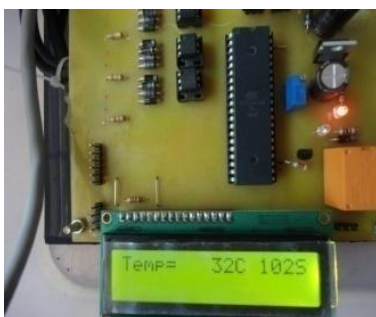

Result on LCD

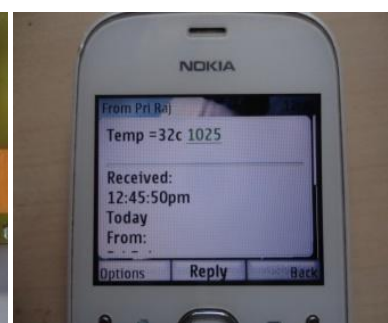

Result of user system

CASE III-Similarly, in case of temperature, when temperature is beyond 60 degree then it will stop its working and message will send as" overheated" on LCD screen as well as user .

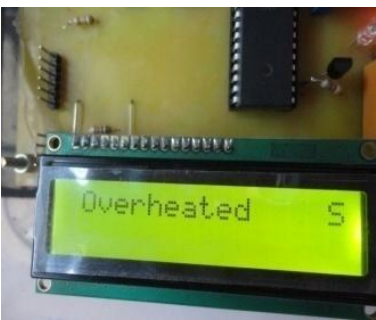

Result on LCD

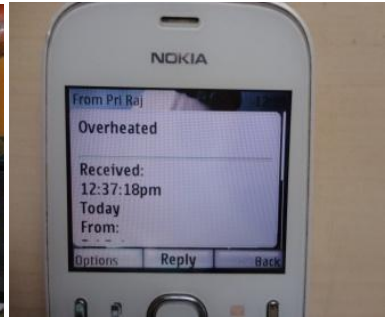

Result of user system

\section{CONCLUSION:}

Here we could conclude that "PARAMETRIC MONITORING OF INDUCTION MOTOR USING GSM" is more advantages as compared to the other monitoring method .Here motor parameter is monitored through GSM modem from remote place as result manpower as well as time requirement will be less. This offers major benefit to both customer and companies in terms of efficiency, reliability, and cost saving and motor is fully protected. 


\section{REFERENCE:}

[1] Petervas, "Parameter estimation, condition monitoring,and diagnosisof electricalmachines." dared on press oxford, 1993. ISBN-10:0198593759, ISBN-13: 978-0198593751.

[2] Atmel Mega16 Datasheet. (www.atmel.com/images/doc2466.pdf-united states)

[3] en.wikipedia.org/wiki/GSM

[4] Search mobilecomputing. techtarget.com.

[5] GSM Module (www.nowsms.com)

[6] ATcommand manual (www.sics.se/ bg/GC75-AT-Commands-R2A.pdf)

[7] Temperature sensors and control ICS -Temp sensor-LM35....(www.ti.com/product/LM35)

[8] Ramazan Bayindir, Member, IEEE, Ibrahim Sefa, Member, IEEE,Ilhami Colak, Member, IEEE and Askin Bektas. (Faults Detection and Protection of Induction Motor Using Sensor)

[9] LCD- Wikipedia, the free encyclopedia. (en.wikipedia.org/wiki/liquid_crystal_display)

[10] ELECTRIC MOTOR-Wikipedia, the free encyclopedia. en.wikipedia.org/wiki/Electric_motor) Similarly , in case of temperature, when temperature is beyond 60 degree then it will stop its working and message will send as" overheated"

[11] www.controleng.com/..../monitoring_induction motor .../5bfaa5385d......11jan 2011.

[12] Yang,W ,Tavner, P.J and Crabtree, C .J . 2009.”An intelligent approach to condition monitoring of large scale wind turbines, European wind energy conference, scientific track."

\section{AUTHORS}

Miss Snehal Lande ${ }^{1}$

Department of EXTC, (B.E., Final Year) Sipna's C.O.E.T., Amravati (India)

Sant Gadgebaba Amravati University, Amravati

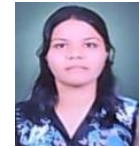

Pooja Jaiswal ${ }^{2}$ Department of EXTC, (B.E., Final Year)

Sipna's C.O.E.T.,Amravati (India)Sant Gadgebaba Amravati University, Amravati

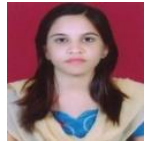

Priyanka Rajgure

Department of EXTC, (B.E., Final Year) Sipna's C.O.E.T.,Amravati (India)

Sant Gadgebaba Amravati University, Amravati

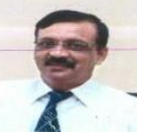

Guided by Dr. S. A. Ladhake,

Sipna's C.O.E.T.,Amravati (India)

Principal 